\title{
SCHMITT E O PROBLEMA DA DEMOCRACIA Nostalgia da transcendência ou a representação como questão para a democracia
}

\author{
Cássio Corrêa Benjamin* \\ ccbenj@yahoo.com
}

RESUMO O artigo analisa a questão da democracia em Carl Schmitt. Para tanto, retoma seu conceito de forma politica que inclui identidade e representação. Após apresentar uma distinção fundamental para a noção de democracia, deriva algumas conseqüencias do contraste com as idéias de Schmitt. A representação e a identidade como formas políticas constituiriam, então, uma impossibilidade para a democracia.

Palavras-chave Democracia; autodeterminação; representação; identidade.

ABSTRACT This article analyses the question of democracy in Schmitt's work. For this purpose, it reviews his concept of political form which includes identity and representation. After presenting a fundamental distinction to the notion of democracy, some consequences are derived from contrast to Schmitt's ideas. The representation and the identity as political form would constitute, consequently, an impossibility for democracy.

Keywords Democracy; self-determination; representation; identity.

* Doutorando em Ciência Política. DCP - UFMG. Artigo recebido em outubro de 2008 e aprovado em dezembro de 2008.

KRITERION, Belo Horizonte, nº 118, Dez./2008, p. 417-441. 
É bastante peculiar a recepção de Schmitt. Grande parte do debate atual em torno de sua obra ressalta o seu anti-liberalismo. Isso ocorre principalmente no mundo anglo-saxão ${ }^{1}$. O problema central, segundo esta recepção, é o ataque sistemático de Schmitt à tradição liberal. Tais intérpretes perceberam muito bem a estrutura não liberal da obra de Schmitt. Esse é um ponto sobre o qual não há dúvidas. Entretanto, o que gostaríamos de desenvolver neste texto é algo um pouco esquecido, gostaríamos de mostrar algo que permanece um pouco na sombra. Trata-se do tema da democracia. Se Schmitt é um pensador anti-liberal, não há consenso de que seja também um crítico da democracia. Há inclusive intérpretes que encontram uma idéia de democracia em Schmitt ${ }^{2}$. Sem dúvida, há um debate de fundo sobre o que significa exatamente democracia. Não se pode criticar ou defender qualquer posição sobre a democracia sem defini-la previamente. Iremos tratar deste tópico a seguir. Antes disso, apenas gostaríamos de esclarecer nossa posição.

O que pretendemos mostrar é como o debate em torno do pensamento democrático em Schmitt contém várias ambigüidades, além de parecer não compreender o percurso feito por este pensador. Schmitt se apropria de uma noção correta e pertinente de democracia para, na verdade, impossibilitála. Quando Schmitt introduz a noção de representação, ele, na verdade, não está tornando a democracia "possível". Ao contrário, ele abre uma frente de crítica direta à democracia. Não há, de forma alguma, qualquer defesa da democracia em Schmitt. É exatamente do oposto que se trata. Schmitt é um dos mais argutos críticos da tradição democrática. E o que torna tal crítica tão interessante é que ela é feita ao coração mesmo da idéia de democracia. Ao introduzir a noção de representação como forma política, oferecendo uma saída para o problema da identidade, ele necessariamente refaz a noção de democracia, tentando explicar o Estado como um ponto entre a identidade e a representação. Relacionando Estado e sua visão específica da representação, Schmitt impossibilita a democracia.

Entretanto, não há crítica sem pressupostos. Afirmar que Schmitt é, na verdade, um autor radicalmente anti-democrático exige revelar de onde se parte. Em suma, criticar Schmitt devido à sua oposição à democracia implica definir o que se entende por democracia. Obviamente, não pretendemos aqui uma definição exaustiva do que seria a democracia. Muito menos retomaremos toda a discussão sobre tal tema. Queremos apenas ressaltar alguns traços

1 Ver, por exemplo, SCHEUERMAN, Between the Norm and the Exception. Há também DYZENHAUS, Legality and Legitimacy.

2 É a posição de KALYVAS, Carl Schmitt and the Three Moments of democracy. 
fundamentais, algumas distinções da tradição democrática. Contudo, mesmo tais características constitutivas já mostrariam bem claramente o que a democracia não pode ser. Isso, e apenas isso, já seria o suficiente para entender a grande distância que separa o pensamento de Schmitt da tradição democrática. Por fim, ao fazer esse breve esboço da noção de democracia não pretendemos apresentar nada de novo ou inusitado. Pretendemos somente retomar alguns traços que já estão presentes na tradição democrática. Trata-se apenas de um exercício de rememoração.

O primeiro aspecto a ser ressaltado na democracia é qual a pergunta a que ela responde. A democracia é uma resposta à crise do fundamento da autoridade ou, em outros termos, uma resposta à crise da justificação das regras. A democracia é uma forma moderna de resposta ao problema do fundamento, já que o moderno é exatamente a descrição do tempo da crise. A democracia é uma forma política que fornece um modo de justificação das regras, quando a justificação tradicional não vale mais. Nesse sentido, se a modernidade pode ser compreendida como o processo dessa crise, a democracia é a sua resposta. Mais precisamente, considerando o direito natural moderno como uma expressão do processo de racionalização que marca o moderno, a democracia significa exatamente o fim dessa tradição - o direito natural -, mas não o fim desse processo. Strauss entende muito bem esse ponto ${ }^{3}$. Seu comentário sobre Rousseau ${ }^{4}$ é a melhor explicação sobre as razões da democracia. Ali fica claro por que a democracia não pode ser compreendida apenas como uma questão sociológica ou como uma questão jurídica. Ela é também uma questão sociológica e jurídica, mas tais âmbitos são como faces de uma estrutura cujo centro está em outro lugar.

Como a democracia fornece essa solução para o problema do fundamento da lei? Como ela consegue ser uma resposta para a crise de legitimidade? A solução que permeia a tradição democrática reside na noção de autodeterminação ou autonomia, essa é a distinção primeira. É legítima a lei ou regra que o próprio grupo estabelece para si mesmo. A lei ou regra, portanto, não está mais fundada na physis antiga, nem em Deus, e também não há mais a certeza sobre alguma lei natural, como no direito natural moderno. $\mathrm{O}$ que resta? Resta a lei que é o resultado da deliberação do próprio grupo, pois

3 Por isso, Strauss, comentando Rousseau, afirma que "a vontade geral toma o lugar do direito natural" (STRAUSS. Natural Right and History, p.286). Esse não é um ponto óbvio. Dahl não percebe essa ruptura e afirma: "historicamente, a justificativa para a igualdade política e a soberania popular tem sido usualmente deduzida de crenças nos direitos naturais" (DAHL. A Preface to Democratic Theory, p.45). Estamos relacionando vontade geral em Rousseau e autodeterminação, como ficará mais claro na seqüência.

4 STRAUSS. Natural Right and History, p.252-94. 
não há nada prévio à deliberação. Isso é o que parte da tradição denominou liberdade 5 . O fundamental, portanto, é a que a lei ou regra seja um produto interno ao próprio grupo. Não há uma regra correta dada anteriormente ou, o que quer dizer o mesmo, dada externamente ao grupo. Ao par interno/ externo corresponde também aquele par contingente/necessário. Do ponto de vista externo, toda lei que seja o resultado da deliberação será percebida como arbitrária. Como não há nenhuma regra anterior à deliberação, pois há somente o princípio da autodeterminação, como já foi dito, então toda nova regra tem como característica essencial o fato de ser contingente, segundo um parâmetro previamente dado ${ }^{6}$. Não se sabe qual será a regra escolhida na deliberação anteriormente ao próprio ato de deliberar. A deliberação é um processo. Do ponto de vista externo, portanto, a escolha que surge como resultado da deliberação será sempre percebida com ex nihilo. A contingência é característica fundamental da democracia ${ }^{7}$. Sem contingência não há democracia, embora a democracia não possa ser reduzida à contingência. Dito de outro modo: a distinção fundamental da democracia reside na noção de causa sui $^{8}$.

Poderíamos definir a democracia, então, primeiramente, como uma espécie de estado de exceção permanente ${ }^{9}$. Exceção permanente e deliberação contínua. Aqui seria levada ao extremo a noção de autodeterminação. Aqui não haveria nenhuma representação. Tampouco haveria Constituição, pois é

5 "A obediência à lei que se prescreve a si mesma é liberdade" (ROUSSEAU. Du Contrat Social, I, VII). Para Strauss, comentando Rousseau: "liberdade é essencialmente auto-legislação" (STRAUSS. Natural Right and History, p.281).

6 Nesse sentido, Rousseau afirma que a vontade geral não pode errar (ROUSSEAU. Du Contrat Social, II, III). Isso não é um absurdo, nem um escândalo. É simplesmente um corolário.

7 Uma outra definição: democracia é ocasionalismo em sua forma pública. Isso porque também a democracia "nega o conceito de causa, ou seja, a obrigação de uma causalidade calculável, mas também de todo vínculo de uma norma" (SCHMITT. Politische Romantik, p.18). O fundamental aqui é a oposição ao conceito de causa. E é o próprio Schmitt quem afirma haver outros possíveis sujeitos do ocasionalismo, além de Deus em Malebranche, como Estado, povo ou sujeito individual.

8 Do ponto de vista interno.

9 A anteposição fundamental aqui é entre exceção e lei. Democracia não é essencialmente o regime da lei, mas aquele da realização do princípio da autodeterminação. Não se sacrifica com essa visão o "respeito à diversidade", tão caro à tradição liberal. O exercício da autodeterminação, por sua vez, implica levar em conta a diversidade. Isso só não ocorreria se se partisse de uma substância perfeitamente homogênea. Esse não é o caso. Exatamente por isso, autodeterminação é permanente composição. Portanto, não é necessária como lugar de partida, do ponto de vista lógico, a noção de lei (ou se se quiser uma tradução possível para o universo sociológico: instituição). O problema óbvio da democracia como exceção permanente é o conflito ou, mais precisamente, a solução do conflito dentro do princípio da autodeterminação. O melhor enquadramento dessa questão reside no problema fundamental da "dupla contingência", constitutivo de qualquer interação em geral e especificamente primordial na situação democrática. Por ser bastante abstrato, é a descrição mais clara e abrangente. Tal questão é trabalhada de forma muito rigorosa e com percepções bastante sugestivas em Soziale Systeme de Luhmann, capítulo terceiro (LUHMANN. Soziale Systeme, p.148-190). 
justamente a idéia de lei dada que se esvaziaria na noção de autonomia como ativismo permanente, como auto-fundação contínua. Por isso, lembramos Sieyès: a nação está sempre em estado de natureza, citado por Schmitt. Por isso, com muito mais exatidão, lembramos Espinosa e seu par de conceitos natura naturans - natura naturata, que foram aproximados de pouvoir constituant - pouvoir constitué ${ }^{10}$. Há nesse momento uma das mais claras vitórias da imanência. Schmitt percebeu muito claramente o problema que tal idéia continha. Além disso, Schmitt aproximou a noção de exceção da de soberania. Mas ela não estava exatamente lá ou, pelo menos, apenas lá. O grande pensador da exceção teve que limitar o escopo dessa noção. Ao contrário disso, podemos afirmar que a exceção reside no coração mesmo da democracia.

A democracia reside no âmbito da imanência ${ }^{11}$. A democracia é a própria expressão da imanência. Isso ocorre não apenas porque na democracia há

10 Schmitt cita esta relação entre os conceitos de Sieyès e Espinosa. Mas, prudentemente, ele aponta a diferença. Ele sabe que tal "metafísica panteísta" é uma expressão clara da imanência. Por isso, ele finaliza a questão afirmando que "a metafísica de potestas constituens como análogo de natura naturans pertence à doutrina da teologia política" (SCHMITT. Verfassungslehre, p.79).

11 Marx, em seus comentários sobre Feuerbach, afirma na primeira tese que para este último "a praxis só é tomada e fixada, na forma em que aparece, como algo sujo e judaico" (MARX. Thesen über Feuerbach, I). Poderíamos afirmar algo semelhante em Schmitt, pois este só percebe a imanência como o que é ligado ao econômico, privado, liberal, subjetivo. E a relação entre imanência e secularização nos impede de concordar com a seguinte afirmação: "a natureza conflitiva e belicosa da existência política está associada ao processo de secularização da época moderna” (FERREIRA. O risco do político, p.248). Nessa passagem, Ferreira comenta $A$ época das neutralizações e despolitizações. Não por acaso, ele tem que perceber uma convivência tensa entre "uma compreensão ontologizante da política" e "uma compreensão historicizante". Não há tal dicotomia. O problema do político não é "um produto da Geistesgeschichte moderna" (FERREIRA. O risco do político, p.248). Por isso, Schmitt tem em alta conta o catolicismo romano e sua forma política. A Igreja tem a capacidade de forma. Ela reside exatamente na "força para a representação" (SCHMITT. Römischer Katholizismus und Politische Form, p.32) Entretanto, em nosso tempo, "a capacidade representativa terminou" (SCHMITT. Römischer Katholizismus und Politische Form, p.32). Novamente, a imanência.. O problema do político, portanto, enquanto uma distinção fundamental, não é um produto, mas se torna crítico no processo de secularização. E isso exatamente porque, na época da imanência, toda e qualquer distinção não consegue mais ocultar o seu caráter contingente, não há mais um ponto transcendente em que se apoiar. Mas, novamente, só há uma, e apenas uma, compreensão do político em Schmitt. Heinrich Meier, bastante incomodado com essa percepção de Schmitt do moderno, com essa questão nunca resolvida em toda a sua obra, tenta encontrar um fundamento (ou distinção anterior) que sustente a distinção do político: o teológico. Schmitt então se torna de fato um teólogo político (MEIER. Carl Schmitt and Leo Strauss). É também um incômodo com a arbitrariedade da distinção do político que move toda a argumentação das notas de Strauss sobre O conceito do político (STRAUSS in MEIER. Carl Schmitt and Leo Strauss). E é também essa não aceitação do caráter constitutivamente contingente e arbitrário do moderno (i.e., imanência e secularização) que revela a posição conservadora de Strauss. Sua grande obra, Natural Right and History (STRAUSS. Natural Right and History), na verdade é uma longa elegia cujo capítulo mais eloqüente é exatamente aquele que não existe: o último capítulo. Ele não pode existir porque parece não haver uma alternativa moderna ao problema do moderno em Strauss (ver também STRAUSS. What is Political Philosophy?). Por isso, o moderno, enquanto imanência, em seu momento mais extremo, é visto negativamente como positivismo e historicismo. Por isso, a sua crítica feroz a Max Weber no início do livro. Mas preceder uma discussão sobre filosofia antiga com um capítulo de crítica a Weber exigiria, por coerência, um último capítulo que ele nunca escreveu. É interessante 
uma igualdade absoluta entre todos aqueles que compõem o grupo. Esse desenho horizontal da igualdade é a imanência. Imanência significa também que não há nenhuma hierarquia já dada de valores. O que significa dizer que não há nenhuma lei ou regra que tenha mais legitimidade que outra. É essa a indeterminação radical da imanência. Se não há nenhuma hierarquia dada da regra ou lei e, em um segundo aspecto fundamental, não há "naturalmente" nenhuma hierarquia dada sobre quem pode fazer a lei ou regra, a única solução que resta é, então, a deliberação. Todos, por serem iguais, deliberam sobre a nova lei que deve valer também para todos. Essa é a única solução não arbitrária já que a alternativa seria a decisão de um ou de um grupo.

É a partir dessa imanência absoluta, da igualdade radical que ela implica, que se pode falar em uma impossibilidade de qualquer dualismo na forma democrática. A conseqüência desse ponto é bem simples: a idéia de representação não pode ser derivada da teoria democrática. Na verdade, a noção de representação é, no mínimo, problemática à tradição democrática, senão completamente antagônica a ela ${ }^{12}$. A representação causa uma fissura inevitável no processo de escolha da lei. O representante torna-se o outro do representado. A representação acaba por desviar para o representante a

como Strauss e Schmitt, por motivos distintos, parecem se caracterizar por uma crítica intensa ao tempo presente. Exatamente por isso, os dois são expressões instigantes das encruzilhadas do moderno.

12 Em Rousseau tal problema se coloca com toda clareza. Por este motivo, consideramos Rousseau um dos principais fundadores, senão o fundador, do que estamos denominando democracia. Em uma passagem do Contrato Social, no capítulo intitulado Dos deputados ou representantes, ele afirma: "os deputados do povo não são e nem podem ser seus representantes, eles são apenas seus comissários, eles não podem concluir nada definitivamente. Toda lei que o povo não ratifica pessoalmente é nula, não é uma lei" (ROUSSEAU. Du Contrat Social, III, XV). A idéia dos deputados como comissários que, exatamente por isso, não podem concluir nada definitivamente é o corolário necessário da noção de autodeterminação. A figura da circularidade aparece na impossibilidade da conclusão definitiva. Nesse sentido, é claramente contra a idéia de representação. Trata-se aqui do poder legislativo, e não do poder executivo. Além disso, é difícil encontrar uma passagem que seja tão oposta ao pensamento de Schmitt. Para este último, como veremos, o representante não pode ser um comissário e é necessariamente independente. Por outro lado, é difícil encontrar um texto mais explícito na oposição entre democracia e representação como em Quelques idées de constitution applicables à la ville de Paris de Sieyès (segundo Pasquino, escrevendo principalmente contra Rousseau). Diz ele: "não pretendemos submeter o governo nacional nem os menores governos municipais ao regime democrático. Na democracia, os próprios cidadãos fazem as leis e designam diretamente seus oficiais públicos. Em nosso plano, os cidadãos fazem, mais ou menos imediatamente, a escolha de seus deputados para a assembléia legislativa. A legislação então deixa de ser democrática e se torna representativa. O povo tem, na verdade, toda a influência sobre os representantes. Ninguém pode obter esta qualidade se não tem a confiança de seus 'commettants', ninguém pode conservar essa qualidade perdendo essa confiança. Mas o próprio povo não pode fazer a lei, menos ainda se encarregar de sua execução" (Sieyès apud PASQUINO. Sieyes et l'invention de la Constitution en France, p.45). O pouvoir commettant, ao lado do pouvoir constituant tem como finalidade "estabelecer o conjunto de regras (Constituição) que rege a ordenação política de uma nação", segundo Pasquino (PASQUINO. Sieyes et l'invention de la Constitution en France, p.46). Mas o que interessa aqui é marcar a anteposição entre democracia e representação. Além disso, Sieyès revela muito bem a consciência plena do problema. Essa questão permanece, de forma explícita ou oculta, em toda a teoria democrática até os dias atuais, sem exceção. 
questão da unidade. Entretanto, isso ocasiona, de uma forma ou de outra, o afastamento do representado. Dito de outro modo: se a representação consegue atingir a unidade, ela só consegue tal feito instaurando uma dualidade. A dificuldade da constituição da unidade na democracia deve ser tomada em toda sua complexidade, sem subterfúgios. A “solução" da representação é uma resposta possível para o problema da unidade, mas permanecerá sempre como um problema para a democracia ${ }^{13}$.

De todo modo, se a possibilidade de um acordo constante sobre todas as questões é impossível, então, é necessária uma instância que tenha a capacidade e a autoridade de decidir sobre tais questões. Além disso, ela deve possuir a prerrogativa de decisão definitiva, de última instância. Ocorre então que tal instância, em um plano democrático, que está necessariamente situado na imanência, permanecerá constantemente em tensão. Uma espécie de paradoxo atravessa todo o processo de decisão: a decisão é legítima se é derivada de tal instância, mas a decisão só é legítima se contar com o acordo daqueles que obedecem. Portanto, como afirma Rousseau, nada pode ser concluído definitivamente. Essa dicotomia é permanente na forma democrática, não há como superá-la. Não cabe a uma teoria democrática dissolvê-la, mas revelá-la, explicitá-la, trazer à tona esta espécie de paradoxo constitutivo da democracia. Sendo assim, usaremos o termo "representação democrática", mas sempre tendo em mente tudo o que foi dito. A representação democrática é, ao mesmo tempo, por isso o paradoxo, uma necessidade e uma impossibilidade.

No momento em que se constitui um corpo de representantes, imediatamente se instaura uma separação insuperável entre representantes e representados. Essa distância não pode ser eliminada de forma alguma, ela estabelece de fato uma divisão entre os dois grupos. O que fazer então? Do ponto de vista de uma visão democrática, não se pode negar tal distinção, mas partir dela. Como a democracia é imanência, o modo de vincular esses dois grupos será, entre outros recursos, a autorização, primeiramente, e formas variadas de prestação de contas. São essas formas de relação que repõem a imanência de modo já não mais imediato. Em uma forma complexa, a unidade só pode ser unidade mediata.

$13 \mathrm{Na}$ verdade, a representação é apenas uma das noções que a democracia leva ao extremo. A outra seria a soberania, na democracia ela toma uma forma paradoxal: a democracia seria uma soberania absoluta - o único regime rigorosamente legibus solutus - e a democracia seria também a completa extinção da soberania, pois aqueles que obedecem são os próprios autores da lei. Mas desse conceito não nos ocuparemos. $\mathrm{O}$ que essas duas noções revelam muito claramente é que a democracia radicaliza e tensiona conceitos que já existiam. Na verdade, a democracia lhes dá um novo sentido. O movimento da democracia é na direção da radicalização desses dois conceitos. 
Há, portanto, uma característica fundamental da representação democrática. A instância superior de decisão não é o ponto final de imputação da unidade, ela sozinha não constitui a unidade. Tal instância superior faz parte da unidade, compõe a unidade em um processo que inclui necessariamente a participação do representado. A unidade se dá, pois, em todo o processo, e não somente na representação. Se se pode utilizar a caracterização de democracia, esta situa-se no processo (não no resultado), refere-se ao processo como um todo. Mais uma vez se percebe por que a imanência coloca em xeque o conceito tradicional de representação.

Não nos enganemos. Schmitt percebeu com clareza o ponto central da democracia. Quando trata da noção da democracia ${ }^{14}$, ele afirma com precisão: "a identidade democrática baseia-se na idéia de que tudo o que há internamente ao Estado como atuação do poder estatal e governo permanece dentro da homogeneidade substancial. Todo pensamento democrático se move, com clara necessidade, em idéias de imanência" "15. A imanência é essencial à idéia de democracia. A democracia é, de fato, a expressão da imanência no mundo ${ }^{16}$. A transcendência é a impossibilidade da democracia. Não há como pensar a democracia com transcendência. Acompanham as idéias de imanência aquelas de emanação. Em última instância, o governo emana do povo. Qualquer tentativa de apresentar uma divisão aqui rompe com a visão democrática. Não é que não existam separações. Mas as divisões não são estruturais, elas devem ser justificadas. Essa é a diferença. A transcendência é a divisão posta como estrutura inerente.

É esse âmbito da imanência que permite a Schmitt avançar sua definição de modo mais preciso: "democracia é identidade de dominantes e dominados, governantes e governados, daqueles que mandam e daqueles que obedecem"17. Como ele diz, é a "igualdade substancial" o traço essencial dessa definição. Aqui não há nenhuma "distinção qualitativa". Isso é a expressão clara da imanência.

De onde vem, então, a "força ou autoridade" daqueles que comandam na democracia? Necessariamente, a autoridade do governo provém "da vontade,

14 Centraremos nossa discussão sobre a democracia no livro Teoria da Constituição, embora em várias obras Schmitt volte ao assunto.

15 SCHMITT. Verfassungslehre, p.237. Doravante, VL.

16 De certo modo, imanência e secularização são os dois lados de uma mesma moeda. Um contraste interessante e esclarecedor seria com essa mesma noção em Weber. Isso não será feito neste artigo. Entretanto, apenas gostaríamos de ressaltar que enquanto a secularização para Schmitt seria uma espécie de ocultamento de uma continuidade, para Weber, ao contrário, seria a explicitação de uma ruptura. Embora um fenômeno de "Ionga duração", exatamente essa ruptura instaura o moderno em Weber.

17 VL, p.234. 
da comissão e da confiança daqueles que são dominados ou governados"18. $\mathrm{O}$ essencial, então, a figura fundamental é que, na democracia, dominados e governados, na verdade, "governam a si mesmos"19. Eis aqui a clara noção de autodeterminação, a figura da circularidade. Por esse motivo, também, a clara noção de emanação, expressão típica e necessária do movimento circular de autodeterminação. Essa definição de Schmitt revela que ele percebeu perfeitamente o significado da democracia. Mostra que Schmitt alcançou seu traço essencial: a circularidade, a autodeterminação.

Entretanto, ele dá uma forma muito específica a essa noção de autodeterminação, a saber, a homogeneidade substancial. Mas como essa homogeneidade só ocorre em raros momentos, ele se vê com uma dificuldade, aliás, a mesma de sempre: a unidade. Mais especificamente, como alcançar a unidade na democracia, ou ainda, como derivar a unidade da imanência? A sua resposta está em lançar mão da noção de representação. A questão que o conceito de representação busca responder é, pois, aquela da unidade.

A igualdade, sem dúvida, é um pressuposto essencial da democracia. A igualdade, como expressão clara da imanência, é a própria razão pela qual surge a noção de autodeterminação. Por isso, a igualdade é um "conceito fundamental" da democracia. Mas, segundo Schmitt, "o conceito democrático de igualdade é um conceito político e, como todo conceito político autêntico, implica a possibilidade de uma distinção"20. Toda unidade pressupõe uma distinção. Como Schmitt sempre exige a unidade, a conseqüência disso é a busca pelo que permite essa unidade na democracia. Schmitt fala, então, não apenas de igualdade, mas de igualdade substancial: "a igualdade democrática é, por conseguinte, uma igualdade substancial" "21. Assim se poderia falar, de fato, em distinção. A expressão concreta dessa unidade na democracia será pois a homogeneidade. "A igualdade democrática é essencialmente homogeneidade e, na verdade, homogeneidade do povo. O conceito central da democracia é povo e não humanidade" ${ }^{22}$. Aqui Schmitt já estabelece uma figura para a unidade na democracia. A democracia não é informe, a homogeneidade expressa sua unidade.

Schmitt, portanto, define a democracia como identidade entre governante e governado, o que decorre necessariamente da igualdade. Entretanto, a homogeneidade é essencial. É a homogeneidade o que daria a figuração 
efetiva da unidade, pois a democracia é um "conceito político autêntico" capaz de uma distinção. Por isso, a noção de "igualdade substancial". A idéia de uma distinção é, como já dissemos, a idéia de unidade e essa seria dada pela homogeneidade.

Gostaríamos de ressaltar dois pontos. Primeiramente, no conceito de democracia de Schmitt, a idéia de "governar a si mesmo", que estamos denominando autodeterminação, sempre tem um limite claro na homogeneidade substancial. Contudo, o desafio de uma teoria democrática é exatamente a unidade sem recair em sua forma mais simples: a homogeneidade substancial. Em outras palavras, como constituir a unidade, partindo do diverso, dentro da imanência. $\mathrm{O}$ outro ponto reside na relação entre governantes e governados. Mesmo reconhecendo que a democracia tem como traço fundamental a imanência, Schmitt afirma: "uma diferenciação entre governantes e governados não pode desaparecer" ${ }^{23}$. Duas questões surgem. Essa necessidade da unidade que não pode se basear puramente na identidade faz com que Schmitt lance mão da noção de representação. O problema da representação, como veremos, é instaurar uma separação intransponível entre governantes e governados. Desse modo, Schmitt realmente alcança a unidade no Estado, mas ao preço de se afastar do que seria a democracia. Nesse sentido, uma unidade não democrática.

A outra questão é a aproximação polêmica que Schmitt realiza entre democracia e ditadura. Para ele, se as pessoas, que governam e dirigem, "encontram a anuência e a confiança do povo ao qual elas pertencem, então, seu domínio pode ser mais rigoroso e duro, seu governo mais decisivo que qualquer monarquia patriarcal ou uma oligarquia cautelosa"24. Sua conclusão: "uma ditadura, particularmente, somente é possível sobre fundamento democrático" 25 . Aqui está a sutil ligação que Schmitt estabelece entre os dois conceitos. Por isso, insistimos que a noção básica da democracia é a autodeterminação. E não se trata de opor, de um lado, democracia e ditadura, de outro, liberalismo. Não se trata aqui de ressaltar o óbvio: o anti-liberalismo de Schmitt (como fazem, entre outros, Scheuerman e Dyzenhaus, já citados). O ponto central é que, fora a questão liberal, há uma impossibilidade conceitual da democracia em Schmitt.

25 VL, p.237. Em sua crítica ao parlamento, Schmitt afirma: "pode existir uma democracia sem o que se denomina sistema parlamentar moderno, e um sistema parlamentar sem democracia. $E$ a ditadura não é o contrário decisivo da democracia, assim como a democracia da ditadura" (SCHMITT. Die geitesgeschichtliche Lage des heutigen Parlamentarismus, p.41). 
Na continuação do argumento, Schmitt afirma que uma ditadura contradiz os princípios liberais porque não é dado ao ditador nenhuma competência normatizada geral, circunscrita e legal. Ao contrário, "a extensão e o conteúdo de sua autorização dependem de sua avaliação. Portanto, não se trata de uma competência no sentido de Estado de direito"26. É impossível exigir mais clareza de Schmitt. Aqui também se observa a estreita relação entre ditadura, soberania e exceção. Mas qual é o equívoco? Se o ditador se move na exceção, ele não é obviamente uma figura do liberalismo. Entretanto, tampouco da democracia. A imanência levada a sério, a autodeterminação conseqüente impede qualquer tipo de ditadura porque a autorização dos governados é um exercício permanente. A autorização do ditador é uma espécie de autorização de si mesmo que supostamente se basearia na autorização dos governados ${ }^{27}$. Mas na democracia não existem suposições: ou a autorização se exerce de modo permanente pelos governados ou ela não existe. Não há meio termo. A ditadura é uma espécie de cheque em branco dos governados para o governante, idéia completamente incompatível com a democracia. Não há cheque em branco na democracia.

Como dissemos, há vários lugares em que Schmitt trata da questão da democracia. Mas nos interessa, particularmente, o momento em sua Teoria da Constituição em que são analisados os dois princípios de forma política (parágrafo 16 - Estado de direito burguês e forma política). Aí se tem, de modo exemplar, tanto o exame da noção de democracia quanto a sua relação com a representação. Schmitt realiza sua exposição da democracia, nesse momento, no contexto de uma crítica ao que ele denomina Estado de direito burguês [Bürgerlicher Rechtsstaat]. Estado de direito burguês concebido como composto por dois princípios: direitos fundamentais e divisão de poderes. Não nos interessam os detalhes desta crítica, mas cabe apenas ressaltar que Schmitt pretende criar uma anteposição, mais uma vez, entre liberalismo e o político. O modo agora é a oposição entre Estado de direito burguês e forma política. Para ele, o Estado de direito burguês não expressa uma forma política e não é uma forma de Estado. O Estado de direito burguês é somente "uma série de limites e controle do Estado, um sistema de garantias da liberdade burguesa e da relativização do poder estatal"28. O que é relevante para nossa discussão está no termo que Schmitt apresenta como oposição a tal Estado, a saber, 
forma política. O que Schmitt pretende mostrar com tal termo? O que ele significa?

Há dois princípios de forma política: identidade e representação. O que Schmitt está relacionando aqui é unidade e forma. Unidade política ocorre quando há forma política, ou seja, quando há identidade ou representação. Estes dois princípios são antepostos, são dois extremos em um contínuo: o máximo de identidade corresponde a um mínimo de representação, o máximo de representação, a um mínimo de identidade ${ }^{29}$. Schmitt dividirá os comentários em duas partes. A primeira, sobre a identidade. A outra, sobre a representação. Faremos um comentário de alguns parágrafos que consideramos mais relevantes. O que estamos querendo mostrar é como a democracia, de fato, não se situa em nenhum lugar entre esses dois extremos da forma política. Não há democracia dentro da forma política. Primeiramente, os parágrafos sobre o conceito de identidade.

Parágrafo primeiro: "Estado é um status determinado de um povo e, na verdade, o status de uma unidade política. Forma do Estado é o modo específico de configuração dessa unidade" ${ }^{30}$. Schmitt afirma que o povo pode alcançar de modos distintos a situação de unidade política. Aqui ele apresenta a sua dicotomia fundamental. Ele precisa desse enquadramento específico do problema da unidade para que sua solução tenha sentido. A primeira forma de unidade é aquela do povo "capaz de ação política", devido a uma "homogeneidade forte e consciente" 31 . A palavra-chave aqui é identidade imediata. Um dos pólos do eixo das formas políticas será essa "identidade imediata". Desse modo, Schmitt apresenta a necessidade do outro pólo já que, em nenhuma situação de fato, ocorre essa unidade imediata dada pela homogeneidade.

Ao aproximar a democracia do que é imediato, Schmitt constrói um quadro teórico de modo a deduzir a necessidade da representação. Não há forma mais clara de dizer isso: "o princípio contrário parte da idéia de que a unidade política do povo, como tal, nunca se pode fazer presente em identidade real e, por isso, deve ser sempre representada pessoalmente por homens" ${ }^{32}$. É fato que não há unidade política "presente em identidade real". A unidade política é sempre identidade construída, elaborada. A identidade não é imediata,

29 Para um comentário detalhado desta relação entre identidade e representação, ver PASQUINO, Die Lehre vom "pouvoir constituant".

30 VL, p.205.

$31 \mathrm{VL}, \mathrm{p} .205$

32 VL, p.205 
a sua fabricação é constante. Contudo, a identidade na democracia é dada exatamente pela participação. Não é a representação, mas o círculo que inclui participação e decisão que constrói a unidade. É um processo dinâmico.

Na continuação, Schmitt cita sua discussão anterior - que não retomaremos - sobre os dois sujeitos do poder constituinte [verfassunggebende Gewalt]: povo e monarca. Quando o povo é sujeito do poder constituinte, "a forma política do Estado se determina pela idéia de uma identidade; a nação está aí; ela não precisa e não pode ser representada, um pensamento que revela sua irrefutabilidade democrática às exposições tão citadas de Rousseau (Contrat Social, III, 15)"33. Por isso, como já dissemos, Rousseau é o ponto mais claro de início do pensamento democrático que, por conseguinte, é sempre moderno. Há governo em Rousseau, mas não há representação. A representação na democracia é sempre um problema. Isso é apenas dedução rigorosa, coerente e lógica. Quanto à monarquia absoluta, segundo Schmitt, essa é representação absoluta. Nela, um representante pessoal realiza a unidade. Então, “' L'État c'est moi' significa: somente eu represento a unidade política da nação" 34 . Aqui, a unidade vem "de cima".

A conclusão de Schmitt é que todo Estado possui elementos estruturais tanto do princípio de identidade quanto do princípio de representação. Todo Estado realiza sua unidade através desses dois movimentos. A partir desse pressuposto, Schmitt avança então o que é o ponto principal de seu argumento: "ambas as possibilidades, identidade e representação, não se excluem, mas são dois pontos de orientação contrários para a concreta configuração da unidade política"35.

Parágrafo segundo: O corolário do parágrafo anterior é que "não há, primeiramente, nenhum Estado sem representação" ${ }^{36}$. E isso vale também em uma democracia direta, na qual "todos os cidadãos ativos estejam reunidos em uma praça" 37 . Segundo Schmitt, "todos os cidadãos ativos reunidos não são, como soma, a unidade política do povo, mas representam a unidade política que está acima do espaço e do instante de uma assembléia reunida"38. Essa é uma afirmação preciosa que revela bem o problema. Aqui se mostra a dualidade estrutural que necessita da representação para se tornar unidade. Os 
cidadãos ativos não são a unidade do povo, mas representam essa unidade. $\mathrm{O}$ que aparece, como aparece, não expressa a essência, por isso, a necessidade da representação. Portanto, a típica dualidade de uma unidade que se encontra acima do espaço e do tempo da assembléia.

Mas, do ponto de vista da democracia, não pode haver tal dualidade. A democracia, na verdade, é um monismo. Sua força e sua fraqueza residem nessa espécie de monismo imanentista em permanente reconstituição. Portanto, a unidade do povo não reside em algo "acima", a unidade se compõe no ato de participação. O povo só existe em ato ${ }^{39}$. Não existe povo que possa ser representado. A unidade do povo é o resultado da participação. Por ser ação, a unidade é sempre dinâmica. A unidade é o processo permanente de construção da unidade. Dito de outra forma, na democracia só existem cidadãos, só existem membros em atividade participativa. O povo não é algo prévio à cidadania, àqueles que participam. A noção primeira da democracia não é a noção de indivíduos. A noção primeira é sempre cidadania, o que significa exatamente participação ${ }^{40}$. É nessa participação que reside esta espécie de, aparentemente paradoxal, estabilidade dinâmica da democracia. O vínculo na democracia, dado pela participação, é, então, sempre um vínculo horizontal, nunca vertical. O que é isso? Imanência.

39 Se fosse possível separar as duas noções, é como se o povo fosse pura energeia, sem dynamis.

40 Nesse sentido, deve-se reconhecer que, na democracia, todos os direitos são políticos (contudo, o início da democracia é uma obrigação, a participação, e não um direito). Isso não apenas em relação ao clássico tríptico de Marshall, a saber, direitos civis, políticos e sociais (MARSHALL. Class, citizenship, and social development), mas também quanto aos direitos humanos. Não existem direitos humanos na democracia, existem direitos políticos. Se a categoria de "humanidade" não chega exatamente a ser estranha à noção de democracia, como Schmitt pretende, pelo menos não é necessária.. Todo direito é, no fundo, sempre político. Somente o declínio do significado da política pode obscurecer esse ponto. E "se podemos denominar liberalismo aquela doutrina política que tem como fato político fundamental os direitos do homem, distintos dos deveres, e que identifica a função do Estado com a proteção ou a salvaguarda desses direitos, então, devemos afirmar que o fundador do liberalismo foi Hobbes" (STRAUSS, Natural Right and History, p.181). Não nos interessa a polêmica em torno do fundador do liberalismo, mas a precisão e concisão da definição de Strauss. Sendo assim, como não perceber que a noção de direitos humanos não é nada mais nada menos que o liberalismo redivivo? Universais? Um autor menos suspeito que Schmitt pode responder: "liberalismo não é um possível fundamento comum para todas as culturas, mas é a expressão política de um conjunto de culturas e completamente incompatível com outros conjuntos ... liberalismo não pode e não deve reivindicar neutralidade cultural. Liberalismo é também uma crença militante" (TAYLOR, The politics of recognition, p.62). O debate atual no âmbito europeu sobre o uso da burka no espaço público só confirma esse ponto. A França caminha na direção da proibição da cidadania aos que se recusam a viver sem a burka. Isso revela que, no limite, mesmo o liberalismo possui o conceito do diferente, do estranho, mas não necessariamente do inimigo. O binarismo é constitutivo de toda configuração política, não há como evitá-lo. É interessante perceber que esse aspecto ativo, esse caráter proselitista do liberalismo - o termo religioso não é casual - parece ter escapado a Schmitt. E é exatamente esse caráter que Ihe dá uma clara conotação política. O liberalismo político sabe distinguir e distingue, de fato, o diferente, como no caso francês. Alguns grupos islâmicos europeus afirmaram que o uso da burka é incompatível com o Islã. De fato, ler o Corão tendo como pressuposto a Revolução Francesa e tendo ao lado a Crítica da Razão Pura faz uma grande diferença. Mas o que é o Islã? O Islã são as interpretações do Islã. Interpretações com ou sem Aufklärung. 
É nesse sentido que Schmitt diz de Rousseau: "o cidadão singular (como sempre ressaltava Rousseau precisamente) não está presente em sua realidade 'natural' como homem singular, mas como cidadão, como citoyen" ${ }^{41}$. Como dissemos, só existem cidadãos na democracia ${ }^{42}$. Mas é significativo que Schmitt não diga que, exatamente por isso, Rousseau negue a representação. Exatamente por só existirem cidadãos, a representação é impossível. Como afirmamos, Rousseau é um dos marcos fundamentais da democracia exatamente por perceber a impossibilidade da representação. Se em figurações políticas complexas alguma noção de representação é inevitável, como dissemos, então só podemos afirmar que a noção de representação democrática, longe de ser uma solução, é a expressão de uma tensão permanente.

Schmitt afirma que "todo deputado é considerado como 'delegado [Vertreter] de todo o povo', ou seja, como representante [Repräsentant]" ${ }^{43}$. Por isso, também, "o sistema de eleição democrática baseia-se em todos os detalhes na idéia de representação" ${ }^{44}$. Com isso, salva-se a unidade. Com isso, perde-se a compreensão do papel do deputado em uma democracia. Essa percepção da representação do todo é estática. Schmitt constrói uma oposição rígida: ou se representa o todo ou se trata do particular. Mas o deputado, em uma democracia, expressa uma parte que deve compor uma totalidade. No sentido de Schmitt, ele não encarna o todo, ele não representa. Nem o deputado, nem o parlamento, que Schmitt também critica ${ }^{45}$. O parlamento não representa, o parlamento é um dos locais essenciais da composição do todo. O todo não é anterior ao processo, mas é o próprio processo. A totalidade na democracia está em permanente recomposição. Não há outro modo de ser na imanência. Essa é a causa inclusive da impossibilidade de qualquer tipo de mandato imperativo. $\mathrm{O}$ mandato imperativo não pode ocorrer porque $\mathrm{o}$ todo está em permanente composição a partir das partes que, exatamente por isso, não podem ser fixas. Não se trata, portanto, do deputado representar o todo. Não há um todo a ser representado. O todo é o processo de totalização permanente.

41 VL, p.206.

42 Estamos relacionando o ponto fundamental da idéia de democracia à estrutura da vontade geral em Rousseau. A rigor, democracia para Rousseau seria apenas uma das formas de governo (ROUSSEAU. Du Contrat Social. III, IV). Quando afirmamos que Rousseau é um dos primeiros a formular a noção de democracia, tal distinção deve ser levada em conta.

43 VL, p.206. Os temos Repräsentation e Vertretung podem ter, em alemão, sentidos próximos. Ambos poderiam ser traduzidos por representação. Mas o "representante", no sentido eminente, é sempre é sempre Repräsentant. Por isso, escolhemos "delegado" para Vertreter.

44 VL, p.207.

45 A crítica à instituição parlamentar é feita de forma mais detalhada em seu livro $A$ situação histórico-intelectual do atual sistema parlamentar (SCHMITT. Die geitesgeschichtliche Lage des heutigen Parlamentarismus). 
Schmitt também afirma que mesmo quando os cidadãos participam de um plebiscito, dizendo "sim" ou "não" a uma questão proposta, mesmo que predomine o princípio de identidade, ainda há elementos de representação. Essa associação entre identidade e plebiscito - e, portanto, a "verdadeira" democracia - é curiosa porque a idéia de participação envolve essencialmente deliberação, troca de comunicação e mudança de posição. Embora sempre sejam associadas formas diretas de decisão a decisões mais democráticas Schmitt não é o único a fazer isso - a democracia, como identidade, reside no modo dessa decisão. Participação, na democracia, implica necessariamente deliberação. Responder "sim" ou "não" a uma pergunta, mesmo que em uníssono, sem uma deliberação permanente, não possui nenhum caráter democrático. Uma decisão unânime pode ser completamente anti-democrática. Plebiscitos podem ser um ótimo exemplo disso. O critério da democracia não está no resultado, mesmo que não haja uma única divergência, o critério está no modo como se realiza o processo.

Passemos agora aos comentários sobre a noção de representação.

Parágrafo primeiro: Schmitt afirma que "a representação só pode ocorrer na esfera da publicidade" 46 . Aqui ele repete a sua distinção: o que é público se diferencia do que é privado, do direito privado e do mero econômico. É nessa direção que é feita a crítica ao parlamento: "um parlamento tem caráter representativo somente se se crê que sua atividade própria resida na publicidade" 47 . Qualquer coisa de secreto, de comitês fechados pode ser importante, mas não representa. Um parlamento assim pode até exercer funções úteis. Entretanto, "ele não é mais representante da unidade política do povo"48.

Porém, do ponto de vista da democracia, o parlamento, como já afirmamos, não representa a unidade política do povo. O parlamento compõe a unidade, como parte do processo. O particular se expressa através dos deputados e busca uma composição no parlamento. O parlamento não é o espaço da representação, no sentido de Schmitt, mas um dos principais locais da produção da unidade, como já dissemos. Conseqüentemente, há outros locais além do Estado. Conseqüentemente, o parlamento não é independente exatamente porque ele não representa. 
Parágrafo segundo: Schmitt aqui revela de forma mais precisa o seu conceito de representação: "A representação não é um fenômeno normativo, não é um processo, não é um procedimento, mas algo existencial. Representar significa tornar visível [sichtbar] e presentificar um ser não visível [unsichtbar] através de um ser de presença pública. A dialética do conceito está em pressupor o não visível como ausente e, ao mesmo tempo, tornar-se presente" 49 . Representar, então, é tornar presente o que se encontra ausente, tornar visível o invisível, fazer aparecer o que é caracterizado pela ausência. Representar é a visibilidade de um ser de presença pública que faz aparecer um ser ausente. Toda presença é sempre o signo de uma ausência, ausência de um ser que não pode aparecer senão através de outro.

O problema dessa noção de representação para a democracia é sua dualidade constitutiva. Esta dualidade da representação é a impossibilidade de qualquer imanência; existe dualidade porque não há imanência. A representação é uma figura de um mundo dual. No fundo, é a própria configuração da dualidade. A imanência não necessita da representação, a imanência não permite a representação, a imanência impossibilita a representação. A imanência é uma espécie de tautologia: há unidade porque a unidade se constitui a partir de si mesma ou não há unidade porque a unidade não pode vir de fora de si mesma.

Portanto, o representante não pode ser independente ${ }^{50}$. Fica clara então a tensão entre democracia e representação. Essa tensão é permanente, ela nunca será anulada ou ultrapassada de algum modo. Compreender a radicalidade do problema da democracia implica compreender a permanência dessa tensão. Se a democracia não pode ser pensada como uma unidade simples, sem conflito, então ela necessita de um ponto de decisão que encerre o conflito. O que na democracia é levado ao limite é a tensão permanente entre a instância que encerra a disputa, por um lado, e uma necessária abertura para nova deliberação ou participação. Por isso, Rousseau: nada pode ser concluído definitivamente. Não há modelo teórico ou arranjo institucional que solucione esse paradoxo porque ele é constitutivo da democracia. A solução desse paradoxo seria ou a simplificação da questão (democracia como estado de exceção permanente, comojá comentamos) ou ofim da democracia (“o representanteé independente", como veremos em Schmitt no parágrafo quarto). O que chamamos então de representação democrática é a expressão desse paradoxo. A representação democrática é claramente paradoxal, essa é sua estrutura. 
Na continuação do parágrafo, Schmitt afirma que só se pode representar aquilo que tem valor, aquilo que tem grandeza, mas nunca algo que se encontre no âmbito do que é privado. Por isso, Schmitt afirma que "na representação, uma alta espécie de ser passa a ter uma aparência concreta" ${ }^{51}$. Mas quem é esse ser? Continuando: "a idéia de representação baseia-se no fato de que um povo existente como unidade política tem uma elevada, vívida e intensa espécie de ser em face da existência natural de qualquer grupo humano que tem vida em comum" 52 . O que é representado, então, é a unidade política do povo.

Parágrafo quarto: "O representante é independente, por isso, não é funcionário, nem agente, nem comissário" 53 . Essa é uma das características centrais da representação para Schmitt que faz com que não se possa, de forma alguma, associá-la à democracia. Com a independência do representante, Schmitt alcança sua pretendida unidade. Com a independência do representante, tem-se o fim da democracia.

É significativa a distinção que Schmitt estabelece: o oposto do representante é o funcionário, o agente, o comissário. O ponto é uma outra distinção mais básica, a saber, a noção de independência. O problema é que, na democracia, aquele que toma decisões no lugar de outro, por estar autorizado, nunca é independente. Sempre haverá, e permanecerá, uma tensão entre certa autonomia dessa decisão e a influência dos afetados por essa decisão sobre a própria decisão. Essa é a tensão permanente da representação democrática. A questão central aqui é a independência daquele que decide ou, dito de forma menos óbvia, a politização da velha disputa entre imanência e transcendência.

A diferença crucial é que, na democracia, ao contrário da representação, a decisão está inserida em um processo. Fora desse processo, tal decisão não tem legitimidade. Por isso, é o processo que constitui a unidade. $\mathrm{O}$ processo é o todo. Deve-se ressaltar que, na democracia, a unidade, como reside no processo, possui um aspecto formal pronunciado. $\mathrm{O}$ cidadão obedece a um conteúdo determinado de uma decisão não porque ele autorizou tal conteúdo específico, mas porque ele autorizou a capacidade de decisão desde que inserida no processo. $\mathrm{O}$ cidadão autoriza o processo ${ }^{54}$. $\mathrm{O}$ que está autorizado é a capacidade de decidir (formalismo) e não o conteúdo da decisão. Nesse

54 Esse é um dos motivos da impossibilidade do mandato imperativo na democracia. 
sentido, a democracia não é o regime do dissenso, esse é um modo equivocado de entender o que ocorre. A democracia é um grande consenso sobre a forma, o dissenso tem que se limitar ao conteúdo, portanto, claramente, nem todo dissenso é permitido. Pode-se discordar e divergir de tudo, menos da forma, do próprio processo. A democracia não é uma anarquia, a democracia não é um caos, a democracia é uma clara e nítida configuração política cuja unidade não vem da representação, mas de si mesma.

Schmitt cita: "Rousseau já havia discorrido no Contrat Social sobre a diferença entre um representante, por um lado, e agentes e comissários, por outro, que estão incumbidos somente de uma comissão de negócios (emploi) e são meros funcionários (officiers) - Livro I, cap. 1 e 18"55. Entretanto, Schmitt não completa o argumento porque ele vai exatamente contra a sua posição. Segundo Rousseau, quanto ao poder executivo: governo ou suprema administração é o exercício legítimo do poder executivo. Ele é representante? Não, pois "isso não é senão uma comissão [commission], um emprego [emploi], no qual, simples funcionários [officiers] do soberano exercem em seu nome o poder do qual ele os fez depositários e que pode limitar, modificar e retomar quando the aprouver. A alienação de um tal direito é incompatível com a natureza do corpo social e contrária à finalidade da associação"56. Quanto ao poder legislativo, como já citamos anteriormente, "a soberania não pode ser representada pela mesma razão pela qual não pode ser alienada. Ela consiste essencialmente na vontade geral e a vontade nunca se representa: ela é a mesma ou ela é outra, não há meio-termo. Os deputados do povo não são e nem podem ser seus representantes, eles são apenas seus comissários [commissaires], eles não podem concluir nada definitivamente. Toda lei que o povo não ratifica pessoalmente é nula, não é uma lei" ${ }^{57}$. Portanto, além da vontade geral só há funcionários e comissões, nunca representantes. Não há representação em Rousseau.

Para Schmitt, a noção de comissão está ligada ao privado, ao particular e, por isso, não é uma representação. Nesse sentido, a instância da decisão superior na democracia não é uma representação, pois não é independente da maneira como quer Schmitt - há controle, há limites. Por outro lado, na democracia, tal instância também não é uma comissão, pois não se trata aqui de expressar o privado. O que é, então, tal ponto último de decisão? O ponto

55 VL, p.213. Parece haver um erro de grafia na edição porque é o livro III do Contrato Social que possui 18 capítulos. Além disso, é no livro III que é feita, de forma mais detida, a discussão sobre representação e comissão.

56 ROUSSEAU. Du Contrat Social, III, I.

57 ROUSSEAU. Du Contrat Social, III, XV. 
superior de decisão na democracia é uma instância autorizada. Onde reside tal autorização, de onde ela retira sua autoridade? Ela é autorizada pelos cidadãos que participam constantemente no círculo do processo democrático. A participação constante impede qualquer tipo de independência. A decisão última só é legítima se inserida nesse processo.

Adistinçãoquesepara público/privadonademocracianãoéa representação, mas a autodeterminação. Nesse sentido, o processo deliberativo significa exatamente a passagem do privado ao público, ou seja, generalização, mas não universalização. Ao mesmo tempo, a unidade não é dada pela representação. Na democracia, o processo é a totalidade, pois é no processo que reside a unidade, é no processo que se constitui a unidade. A unidade, portanto, não é dada exclusivamente pela instância última de decisão. Essa instância faz parte do processo.

Parágrafo quinto: "Também somente o príncipe absoluto é representante da unidade política do povo; ele sozinho representa o Estado. O Estado tem, como diz Hobbes, 'sua unidade na pessoa do soberano'; ele é 'united in the Person of one Sovereign'. A representação produz [bewirkt] a unidade, porém é sempre a unidade de um povo em situação política o que é produzido. O personalismo do Estado não reside no conceito de Estado, mas na representação" 58 . Na continuação, "o valor da representação baseia-se na publicidade e personalidade que dão à vida política seu caráter" 59 .

Coerentemente, Schmitt afirma que a representação produz a unidade. Com isso, perde-se qualquer relação possível com a democracia. Nesta, a unidade não é produzida por um ponto hierárquico superior, mas por um processo que envolve e abarca todos. A questão está exatamente no significado de imanência para a constituição da unidade. Além disso, a ligação entre personalismo, representação e unidade ocupa um espaço especial nos escritos de Schmitt. A capacidade representativa está ligada à pessoa, mas na medida em que ela expressa algo que vem "de cima". O que há de valor está além daquele que o expressa, mas literalmente só se personifica através dele. A pessoa que representa "resolve" o problema da dualidade, liga os dois âmbitos separados. Por isso, não existe lugar para o personalismo na imanência, não existe personalismo na democracia. 


\section{Considerações finais: Catolicismo Romano e Forma Política ou a re- presentação como solução para a unidade}

A Igreja católica para Schmitt é uma complexio oppositorum. Isso revela uma supremacia formal do catolicismo, claramente institucional e jurídica, cuja base é exatamente o princípio da representação. É a representação que torna a Igreja capaz de forma, capaz de unificar os opostos. Forma é unidade. Haveria, então, na Igreja uma reunião de idéia, política, autoridade e ethos da convicção. Mas afinal o que a Igreja representa? Em que, em última instância, ela baseia sua autoridade?

A força para a forma é a força da representação. A Igreja "representa o próprio Cristo pessoalmente" ${ }^{" 60}$. O Papa é o vigário de Cristo. A Igreja realizaria uma junção exemplar entre cargo e autoridade. Então, ao mesmo tempo em que desvincula ofício e carisma, ela vincula a pessoa que ocupa o cargo ao próprio Cristo. Aqui a representação, de fato, funda a autoridade porque é índice de algo superior. O representante é símbolo, a representação é simbólica. A pessoa é, literalmente, a personificação de algo superior ou, dito de outro modo igualmente óbvio, a personificação só ocorre através de uma pessoa, mas não de qualquer pessoa. Portanto, "só uma pessoa pode representar em sentido eminente - para diferenciar da simples delegação - e, na verdade, representar uma pessoa que possui autoridade ou uma idéia que, na medida em que é representada, exatamente, personifica" ${ }^{\prime 6}$.

Como a representação é relacionada a algo superior, o povo não é fonte da autoridade: os representantes da Igreja "não derivam do povo a sua autoridade" 62 . Em um sentido mais amplo, não há autorização do poder da Igreja, há representação. Schmitt expressa de modo claro essa idéia: A Igreja "representa, conseqüentemente, 'a partir de cima" "'63. A abertura para a transcendência é fundamental. Na Igreja, por conseguinte, um conjunto de noções se entrecruza e constitui sentido: representação, forma política, transcendência, totalidade, idéia.

Mas que fique claro, Schmitt não transpõe essa estrutura para o Estado. Entretanto, aponta aproximações. De fato, a Igreja "quer viver com o Estado em comunidade singular, estar diante dele como parceira em duas representações" ${ }^{\prime 64}$. Na Teoria da Constituição, há semelhanças na estrutura representativa. Há um

60 SCHMITT. Römischer Katholizismus und politische Form, p.32.

61 SCHMITT. Römischer Katholizismus und politische Form, p.36.

62 SCHMITT. Römischer Katholizismus und politische Form, p.43.

63 SCHMITT. Römischer Katholizismus und politische Form, p.43.

64 SCHMITT. Römischer Katholizismus und politische Form, p.42. 
ponto superior, a representação, e os representados. A unidade é dada pela representação da unidade, a unidade é criada pela representação. A diferença crucial é que, na Igreja, o Papa, que é único, representa a unidade de Cristo. A representação é aberta para a transcendência. No caso do Estado, o que se representa é a unidade do povo.

O problema reside no fato da democracia, devido à imanência, quebrar o esquema representativo dualista. A representação de Cristo pode ser a base da autoridade pessoal e institucional do Papa na Igreja. Mas, na democracia, o fundamento da obediência do povo só pode vir do próprio povo. Aqui o esquema vertical da representação é curto-circuitado. A imanência não conta com a abertura para cima, a figura-chave aqui, ao contrário, é aquela do círculo: "a obediência à lei que se prescreve a si mesma é liberdade" 65 . A unidade do povo não pode ser representada, muito menos criada pelo representante.

Schmitt sutilmente aproxima duas estruturas de representação díspares. Entretanto, na democracia, a unidade do povo só pode ser criada continuamente através da participação, deliberação, decisão. Só existe povo em ato. A participação é um imperativo da democracia porque a unidade só pode ser criada de forma imanente. Há uma dinâmica e permanente vinculação horizontal. A representação democrática não representaria, nos termos de Schmitt, a unidade do povo porque tal unidade não vem de cima, mas de si mesma. A circularidade impede a representação.

O reconhecimento da perda da transcendência no Estado faz com que Schmitt permaneça sempre em tensão. O representante e o soberano não contam mais com o fundamento da transcendência. Isso arremessa Schmitt para o centro do moderno ${ }^{66}$. O que resta? Resta a representação sem transcendência. Resta o soberano que, exatamente pela ausência da transcendência, é decisionista. Resta o conceito do político que é formal. Há vários lugares vazios em Schmitt ${ }^{67}$. Ao afirmar que os conceitos políticos são conceitos

65 ROUSSEAU. Du Contrat Social, I, VII.

66 O desconforto com essa perda da certeza no moderno não precisa estar apoiado em uma transcendência. Esse é o ponto de discussão entre Schmitt e Strauss. Ver STRAUSS. Notes on Carl Schmitt, The Concept of the Political. De fato, Strauss aponta o seu lugar de crítica como sendo o campo da filosofia política, sem transcendência. Mas a questão permanece: qual filosofia política?

67 Este momento necessário de arbitrariedade nas figuras schmittianas evidencia essa questão. Quando, por exemplo, Schmitt ressalta a anterioridade da decisão sobre a norma, podemos perguntar: em que se funda a decisão? Se se trata de autoritas, non veritas facit legem (SCHMITT. Politische Theologie, p.39), então, em que se funda a autoritas? Se ela se funda a si mesma ou, alternativamente, se institui a partir do "nada", então, é inevitável reconhecer seu caráter arbitrário. A arbitrariedade é constitutiva. Ferreira nega essa arbitrariedade citando um trecho de Sobre os três modos de pensamento científico do direito (FERREIRA. O risco do político, p.124). O problema desse texto é que Schmitt está tentando se afastar de seu decisionismo anterior. De todo modo, não se trata, de fato, da defesa da mera força, mas o critério da ordem não está claro. Se ele é apenas a capacidade de produzir "tranqüilidade, segurança e ordem" 
teológicos secularizados ${ }^{68}$, Schmitt levanta uma tese polêmica. Mas esquemas conceituais típicos da transcendência, ao serem deslocados para o âmbito da imanência, não têm o mesmo sentido. Isso explica as críticas e observações de Strauss, Löwith ${ }^{69}$ e Meier, entre outros, sobre as bases e os fundamentos do pensamento de Schmitt. Os paradoxos da democracia não são fortuitos, são a rigorosa conseqüência lógica da imanência ${ }^{70}$. Schmitt parece se mover entre o reconhecimento da perda da transcendência (por esse motivo, Schmitt é moderno) e a rejeição da imanência. Por isso, a nostalgia da transcendência.

Se, na democracia, por um lado, a representação é um problema, por outro, a democracia direta é uma impossibilidade. É sobre este terreno inseguro que se constrói a teoria democrática. Estas são as dificuldades da imanência. E como mostramos, o nivelamento feito por Schmitt da imanência com a técnica, o econômico e o particular obscurece um ponto crucial. A democracia não pertence ao âmbito privado, não se reduz à técnica. Entretanto, é a mais clara expressão da imanência. Por isso, sempre moderna. Não há democracia antes da vontade geral de Rousseau ${ }^{71}$. Portanto, a impossibilidade da democracia é

(SCHMITT. Über die drei Arten, p.23), como dito na seqüência, essa ordem se aproxima de qualquer ordem, essa unidade se avizinha de uma unidade qualquer. Não deixa de ser interessante observar a proximidade, inicialmente improvável, de Kelsen nesse aspecto. A decisão no decisionismo schmittiano e a norma fundamental (Grundnorm) kelseniana têm a mesma função e padecem de problemas semelhantes. A discussão gira em torno da procura de um início que não é iniciado, a persistente questão aristotélica do primeiro motor (proton kinoun) que move, mas não é movido. Colocar voluntas antes de ratio não elimina a pergunta sobre o fundamento de voluntas. Por que, então, não admitir claramente a arbitrariedade constitutiva dessas figuras? Usar adjetivos como "existencial" e "espiritual" - típicos da linguagem romântica, diga-se de passagem - apenas encobre a questão.

68 "Todos os conceitos expressivos da moderna doutrina do Estado são conceitos teológicos secularizados" (SCHMITT. Politische Theologie, p.43).

69 De Löwith, The Occasional Decisionism of Carl Schmitt.

70 Do ponto de vista lógico, na imanência, os meta-níveis são expostos à sua contingência, o que ocasiona a perda da capacidade de distinguir ou desfazer paradoxos. Aquela expressiva e bela figura da imanência, por exemplo, figura de dois lados de Sieyès - poder constituinte e poder constituído - é fonte infinita de paradoxos. O poder constituinte está fora ou dentro da lei? O poder constituinte controla o poder constituído ou pode ser limitado por ele? O poder constituinte é superior à Constituição ou pertence a ela? O poder constituinte se situa na exceção, está em "estado de natureza" permanente ou é regulado pela lei? As semelhanças com o soberano de Schmitt não são fortuitas. Logicamente, cumprem a mesma função.

71 Dizer que a democracia se inicia no mundo grego revela pouco entendimento dos gregos e nenhum entendimento da democracia. Novamente, Strauss revela uma compreensão precisa e abrangente do processo. Ele situa em Rousseau o início da "segunda onda da modernidade". Ela é a base tanto da filosofia do idealismo alemão quanto do romantismo. Em primeiro lugar, esse movimento é sempre "um retorno do mundo da modernidade para formas pré-modernas de pensamento... e o romantismo como um todo é primeiramente um movimento de retorno às origens." Entretanto, "em todos esses casos, o retorno ao pensamento pré-moderno foi somente o passo inicial de um movimento que levou, conscientemente ou não, a uma forma muito mais radical de modernidade - a uma forma de modernidade que era ainda mais estranha ao pensamento clássico do que aquele pensamento dos séculos dezesseis e dezessete tinha sido". (STRAUSS. What is Political Philosophy?, p.50). Aqui se situa o início da democracia. A insistência de Schmitt nos aspectos subjetivos do romantismo o impediu de perceber que havia algo mais em jogo ali. Reduzir a imanência a subjetivismo só obscurece o fato de que só há democracia porque há imanência. O romantismo, então, não é "metonímia dos tempos modernos" (LIMA. Limites da voz, p.149) porque o moderno não pode ser limitado aos aspectos subjetivos do romantismo, como visto por Schmitt. 
uma questão específica em Schmitt que não pode ser confundida com sua crítica ao liberalismo. A democracia não se situa entre a identidade e a representação, nos termos de Schmitt. Se, para ele, não há Estado sem representação, então, não há Estado que seja democrático. Não há democracia em Carl Schmitt.

\section{Referências}

DAHL. A Preface to Democratic Theory. Chicago: The University of Chicago Press, 1956.

DYZENHAUS, D. Legality and Legitimacy. Carl Schmitt, Hans Kelsen and Hermann Heller in Weimar. Oxford: Oxford University Press, 2003.

FERREIRA, B. O risco do político. Crítica ao liberalismo e teoria política no pensamento de Carl Schmitt. Belo Horizonte: Editora UFMG, 2004.

KALYVAS, A. "Carl Schmitt and the Three Moments of Democracy". Cardozo Law Review, 21: 5-6 (2000).

LIMA, L. C. Limites da Voz: Montaigne, Schlegel. Rio de Janeiro: Rocco, 1993.

LÖWITH, K. "The Occasional Decisionism of Carl Schmitt". In: WOLIN, R. (Ed.). Martin Heidegger and European Nihilism. New York: Columbia University Press, 1995, p.137-169.

LUHMANN. N. Soziale Systeme. Grundriss einer allgemeinen Theorie. Frankfurt am Main: Suhrkamp Verlag, 1987.

MARSHALL, T. H. Class, citizenship, and social development. New York: Anchor Books, 1965.

MARX, K., ENGELS, F. “Thesen über Feuerbach”. In: Werke. Band 3. Berlin: Dietz Verlag, p.5-7.

MEIER, H. Carl Schmitt \& Leo Strauss. The hidden dialogue. Chicago: The University of Chicago Press, 1995.

PASQUINO, P. "Die Lehre vom "pouvoir constituant" bei Emmanuel Sieyès und Carl Schmitt". In: Complexio Oppositorum. Über Carl Schmitt. Berlin: Duncker \& Humblot, 1988, p.371-385.

PASQUINO, P. Sieyes et l'invention de la Constitution en France. Paris: Édition Odile Jacob, 1998.

SCHEUERMAN, W. Between the Norm and the Exception. The Frankfurt School and the Rule of Law. Cambridge: The MIT Press, 1994.

SCHMITT, C. Die geitesgeschichtliche Lage des heutigen Parlamentarismus. Achte Auflage. Berlin: Duncker \& Humblot, 1996.

SCHMITT, C. Politische Romantik. Sechste Auflage. Berlin: Duncker \& Humblot, 1998.

SCHMITT, C. Politische Theologie. Vier Kapitel zur Lehre von der Souveränität. Siebente Auflage. Berlin: Duncker \& Humblot, 1996.

SCHMITT, C. Verfassungslehre. Neunte Auflage. Berlin: Duncker \& Humblot, 2003. 
SCHMITT, C. Über die drei Arten des rechtswissenschaftlichen Denkens. Dritte Auflage. Berlin: Duncker \& Humblot, 2006.

STRAUSS, L. Natural Right and History. Chicago: The University of Chicago Press, 1965.

STRAUSS, L. "Notes on Carl Schmitt, The Concept of the Political". In: MEIER, H. Carl Schmitt \& Leo Strauss. The hidden dialogue. Chicago: The University of Chicago Press, 1995, p.89-120.

STRAUSS, L. "What is political philosophy?". In: What is Political Philosophy? and other studies. Chicago. The university of Chicago Press, 1988, p.9-55.

TAYLOR, C. "The Politics of Recognition". In: Multiculturalism. Examining the politics of recognition. Princeton: Princeton University Press. 